\title{
Analysis of the efficacy of ozone therapy on different types of lumbar disc herniation: a new guidance is coming? [abstract]
}

\author{
Kenan Hao, Huan Liu, Yang Yang, Qingle Zeng, Xiaofeng He
}

China

\section{ABSTRACT}

\section{OPEN ACCESS}

\section{Citation}

Hao K, Liu H, Yang Y, Zeng Q, He X. Analysis of the efficacy of ozone therapy on different types of lumbar disc herniation: a new guidance is coming? [abstract]. Proceedings of The World Conference on Ozone Therapy in Medicine, Dentistry and Veterinary. Ancona (Italy). September 22nd - 23rd - 24th , 2017. J Ozone Ther. 2019;3(4):26. doi: $10.7203 /$ jo3t.3.4.2019.15506

\section{Academic Editor} Jose Baeza-Noci,

School of Medicine, Valencia University, SPAIN

\section{Editor}

World Federation of Ozone Therapy, Bolgna, ITALY

\section{Received}

June 17, 2019

\section{Accepted}

December 08, 2019

\section{Published}

December 30, 2019

\section{Intellectual Property}

Kenan HaO.

This is an open access article distributed under the terms of the Creative Commons Attribution License (CC BY 4.0), which permits unrestricted use, distribution, and reproduction in any medium, provided the original author and source are credited.

\section{Author Information}

ozonetherapy @126.com
Objetive: To investigate the sub-types of lumbar disc herniation, compare efficacies of ozone treatment in various types of lumbar disc herniation and analyze the mechanisms.

Methods: A total of 250 patients (159 males, 91 females; age range: 14 - 85 years) diagnosed of lumbar disc herniation from January 2009 to Jun 2014 in Nanfang Hospital were enrolled.

Disc Lesions, classified by Magnetic Resonance examinations and images when injecting ozone under Digital Subtraction Angiography, were divided into four types:

- Type I: Non- prominent nucleus pulposus with ruptured fibre ring

- Type II: Prominent nucleus pulposus with ruptured fibre ring

- Type III: Non-prominent nucleus pulposus with Non-ruptured fibre ring

- Type IV: Prominent nucleus pulposus with Non-ruptured fibre ring

All patients underwent intradiscal and paravertebral injection of oxygenozone.

Visual Analogue Scale (VAS) weighted score was administered for the measurement of low back pain before treatment, and the evaluation of efficacy respectively at 1 week, 1 month, 6 month and 12 month follow-up period.

Results: Most of the patients (about 4/5) showed better response to ozone treatment. Herniated disc shrinkage was obtained among type II and IV. The type II had the most reduction of average score while the type III had the least. The proportion of patients who had once experienced pain relief at the follow up interval, namely the curative efficacy, showed significant difference: type I occupied the most, type IV occupied the least.

Conclusions: Ozone treatment is effective and safe for all types of lumbar disc herniation, but the efficacies are various in different types, of which type I is the best and type IV is the worst. 